\title{
Mixed sclerosing bone dystrophy with extra-skeletal manifestations
}

INSERM

\section{Source}

INSERM. (1999). Orphanet: an online rare disease and orphan drug data base. Mixed sclerosing bone dystrophy with extra-skeletal manifestations. ORPHA:324364

A rare, genetic, primary bone dysplasia with increased bone density disorder characterized by bone abnormalities, including metaphyseal plaques, osteopathia striata, marked cranial sclerosis, and sclerosis of the ribs and long bones, as well as macrocephaly, cleft palate, hearing loss, developmental delay, and facial dysmorphism (hypertelorism, prominent forehead, wide nasal bridge). Hypotonia, tracheo/laryngomalacia, and astigmatic myopia are also associated. 